\title{
Breast Cancer Risk Factors among Ugandan Women at a Tertiary Hospital: A Case-Control Study
}

\author{
Moses Galukande ${ }^{a}$ Henry Wabingab ${ }^{b}$ Florence Mirembe ${ }^{c} \quad$ Charles Karamagi $^{d}$ \\ Alexzander Asea ${ }^{\mathrm{e}}$ \\ Departments of a Surgery, b Pathology and ${ }^{\mathrm{c} O b s t e t r i c s}$ and Gynaecology and ${ }^{\mathrm{d}}$ Clinical Epidemiology Unit, Makerere \\ University College of Health Sciences, Kampala, Uganda; ${ }^{\mathrm{e} T e x a s ~ A \& M ~ H e a l t h ~ S c i e n c e ~ C e n t e r ~ C o l l e g e ~ o f ~ M e d i c i n e, ~}$ \\ Bryan, Tex., USA
}

\section{Key Words}

Breast cancer risk factors · Ugandan women · Sub-Saharan Africa

\section{Abstract}

Background: Although East Africa, like other countries in sub-Saharan Africa, has a lower incidence of breast cancer than high-income countries, the disease rate is rising steeply in Africa; it has nearly tripled in the past few decades in Uganda. There is a paucity of studies that have examined the relation between reproductive factors and breast cancer risk factors in Ugandan women. Objective: To determine breast cancer risk factors among indigenous Ugandan women. Methods: This is a hospital-based unmatched case-control study. Interviews were conducted between 2011 and 2012 using structured questionnaires. Patients with histologyproven breast cancer were recruited over a 2-year period. Logistic regression was used to estimate odds ratios (ORs) and $95 \%$ confidence intervals (Cls). Results: A total of 350 women were recruited; 113 were cases and 237 were controls. The mean age was 47.5 years (SD 14) for the cases and 45.5 years (SD 14.1) for the controls. The odds of breast

\section{KARGER}

E-Mail karger@karger.com www.karger.com/ocl

\section{(c) 2016 The Author(s) \\ Published by S. Karger AG, Basel 0030-2414/16/0906-0356\$0/0}

This article is licensed under the Creative Commons Attribution 4.0 International License (CC BY) (http://www.karger.com/Services/ OpenAccessLicense). Usage, derivative works and distribution are permitted provided that proper credit is given to the author and the original publisher. cancer risk seemed lower for those who breastfed (adjusted $\mathrm{OR}=0.04 ; 95 \% \mathrm{Cl}: 0.01,0.18)$. There was no significance for early age at first full-term birth (adjusted OR $=1.96 ; 95 \% \mathrm{Cl}$ : $0.97,3.96 ; p=0.061$ ), and urban residence carried no increased odds of breast cancer either $(p=0.201)$. Conclusion: Breastfeeding seems to be associated with reduced odds of breast cancer.

(C) 2016 The Author(s)

Published by S. Karger AG, Basel

\section{Introduction}

Although in Uganda women have a lower incidence of breast cancer than in Canada, the USA, and Western Europe [1], the disease rate is rising steeply; it has nearly tripled in a short period of time from 11 per 100,000 in 1962 to 31 per 100,000 in 2006, and it is predicted to become the commonest non-HIV-related malignancy among Ugandan women within less than a decade [2]. The factors fueling this rapid rise are not fully known. Exploring risk factors in this setting may provide some clues.

There is a paucity of studies that have examined risk factors for breast cancer in Ugandan women, and even 
Fig. 1. Flow diagram showing the recruitment of participants.

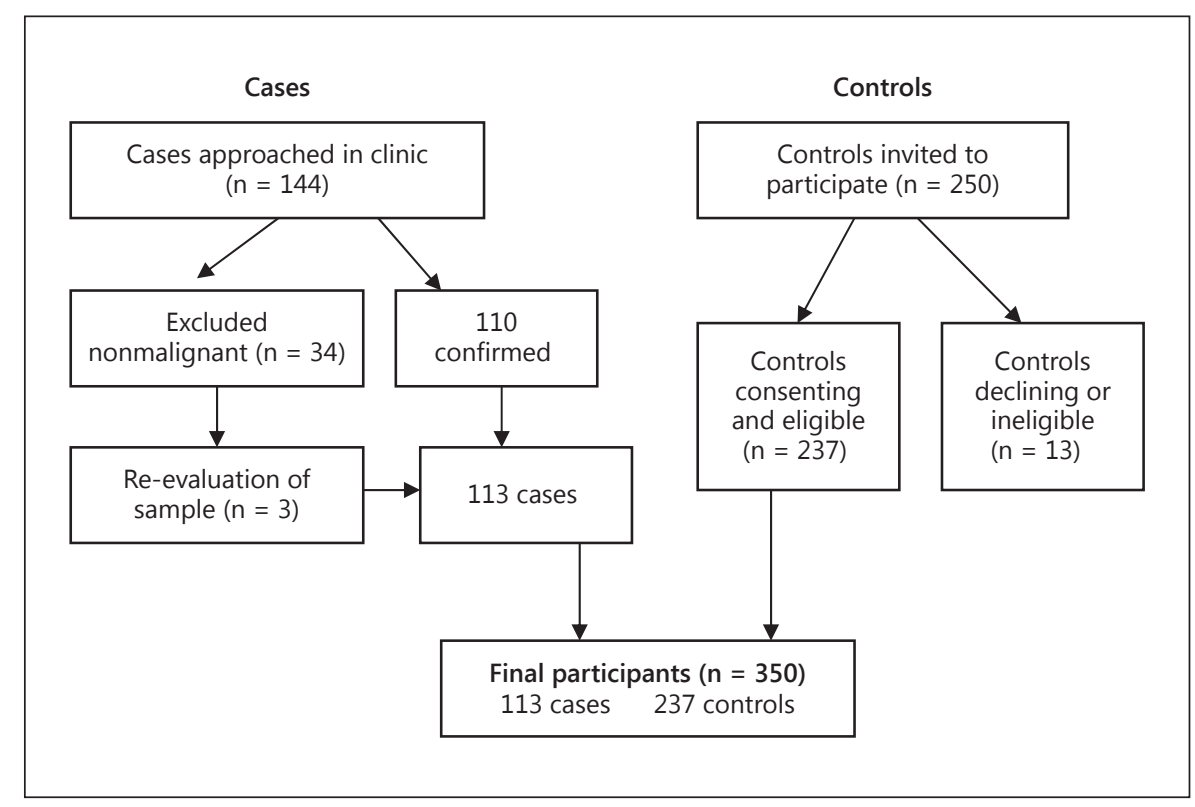

fewer have examined the association with reproductive factors in sub-Saharan Africa [3, 4]. In Uganda, parity and breastfeeding were examined in one study done 20 years ago, suggesting that parity was not protective but breastfeeding was [5].

In this study, we examined parity, breastfeeding, late age at first full-term birth (AFB), alcohol use, combined oral contraceptive $(\mathrm{CoC})$ use, rural residence, and body mass index (BMI) as possible risk factors associated with breast cancer.

\section{Study Site Context}

Uganda is a landlocked country straddling the equator in East Africa. The country's area is $241,040 \mathrm{~km}^{2}$ and it currently has a population of $32,709,865$ people [6]. With a total fertility rate of 6.7 births per woman - the second highest in the world - Uganda is due to double its population by 2037 (starting with the numbers from 2006) [7]. Its capital, Kampala, is a city of 1.4 million people located in the south-central region of the country. Despite achieving a 5.8\% gross domestic product growth rate in 2010, almost one third of the country still live in poverty (defined as living on less than USD 1.25 per day) [5]. A total of $85 \%$ of the population live in rural areas, and most of them work in the agriculture sector [8]. Uganda ranks 143rd among the 169 countries surveyed for the 2010 Human Development Index $[9,10]$. Life expectancy has slowly been increasing to its current level of 53 years, although half of the population is between the ages of 0 and 14 years. The Ugandan health system was developed by public and private providers; most health care is free. Referrals for cancer care are mostly sent to the Mulago National Referral Hospital and the Uganda Cancer Institute (UCI).

\section{Methods}

Design

This is a case-control study.

Setting

The study was conducted at two tertiary care institutions: the Mulago National Referral Hospital and the UCI. Together the two sites may receive up to 200 incident cases per year; however, there may be high dropout rates.

\section{Study Sample}

Cases were identified prospectively from women with a confirmed histological diagnosis of invasive breast cancer during the study period from September 2011 to December 2012. Controls were randomly selected from patients who visited other units or departments, especially surgical outpatient units where post-traumatic and other surgical conditions are attended to; obstetrics and gynecology wards were excluded. All eligible controls had no cancer ailments; they were not chosen from the UCI. The controls were considered to come from the same catchment area as the cases. The clients were ethnically and socioeconomically diverse and represented the diversity of the Ugandan population and the patient population that comes to the Mulago Hospital and the 
UCI; the Mulago Hospital and the UCI are separate institutions, although they are located on the same campus and collaborate in care provision.

\section{Inclusion Criteria}

Controls were female, without any type of cancer as determined from their medical histories and general physical examination, and able to give informed written consent.

\section{Study Variables}

The following variables were considered: age, area of residence (rural or urban), BMI, and alcohol consumption. In addition, parity, menarche, AFB, CoC use, and breastfeeding were included as reproductive factors.

Age was categorized as $\leq 50$ or $>50$ years (a proxy for menopausal status). BMI was determined by measuring weight in kilograms per height in meters squared. Alcohol use was assessed through history taking, and the response was either 'yes' or 'no' (amounts were not quantified). Parity was determined by the number of pregnancies a participant had ever had. Menarche was defined as the age at which the first menses occurred. AFB was completed years when the first full-term birth ( $\geq 37$ weeks of gestation) occurred. For breastfeeding it was assessed whether or not it was done, as well as its duration if performed. All these parameters were gathered through history taken from the study participants using a precoded and pretested questionnaire.

\section{Laboratory Methods and Quality Assurance}

Hematoxylin and eosin staining was performed to confirm the diagnosis of invasive breast cancer. The histological type and grade were determined. All the histological slides were investigated by an experienced consultant pathologist and laboratory technicians, and the tumors were classified according to the Nottingham modification of the Scarff-Bloom-Richardson criteria [11]. Based on histology, the tumors were classified into the following groups: invasive ductal carcinoma (not otherwise specified), lobular, medullary, papillary, and colloid.

\section{Data Analysis}

Demographic factors and potential confounding variables were compared between cases and controls using $\chi^{2}$ tests for categorical variables. Logistic regression models were used to examine the relationship of breast cancer risk to the selected reproductive factors. Odds ratios (ORs) and 95\% confidence intervals (CIs) were computed as measures of association from the logistic model. A multivariable logistic regression model was used and included the following variables: age, parity, breastfeeding, menarche, $\mathrm{AFB}, \mathrm{CoC}$ use, and BMI. Statistical significance was considered if $\mathrm{p} \leq 0.05$.

Data were occasionally missing for all variables; no further analyses were done for missing data. In the final analysis, women who had never given birth were excluded.

\section{Ethical Considerations}

The study was approved by the Institutional Review Boards of Makerere University and the Uganda National Council of Science and Technology (UNCST) and thus meets the standards of the Declaration of Helsinki in its revised version of 1975 and its amendments of 1983, 1989, and 1996. All participants gave informed written consent.
Table 1. Demographics, reproductive factors, and breast cancer (Kampala 2012)

\begin{tabular}{|c|c|c|c|}
\hline Variable & $\begin{array}{l}\text { Cases } \\
(n=113)\end{array}$ & $\begin{array}{l}\text { Controls } \\
(\mathrm{n}=237)\end{array}$ & $\mathrm{p}$ value \\
\hline Age & & & 0.906 \\
\hline$<50$ years & $70(62)$ & $149(63)$ & \\
\hline$\geq 50$ years & $43(38)$ & $88(37)$ & \\
\hline Setting & & & 0.001 \\
\hline Rural & $62(55)$ & $150(64)$ & \\
\hline Urban & $50(45)$ & $85(36)$ & \\
\hline Country region & & & 0.037 \\
\hline Central & $67(59)$ & $130(55)$ & \\
\hline Western & $17(15)$ & $62(26)$ & \\
\hline Northern & $11(8)$ & $24(10)$ & \\
\hline Eastern & $18(16)$ & $20(8)$ & \\
\hline Parity & & & 0.343 \\
\hline 1 & $11(12)$ & $18(9)$ & \\
\hline $2-4$ & $34(39)$ & $71(35)$ & \\
\hline$\geq 5$ & $44(49)$ & $122(56)$ & \\
\hline Menarche & & & 0.507 \\
\hline$\leq 14$ years & $53(31)$ & $134(58)$ & \\
\hline $15-16$ years & $40(39)$ & $71(31)$ & \\
\hline$\geq 17$ years & $11(10)$ & $26(11)$ & \\
\hline BMI & & & 0.345 \\
\hline$\leq 18.5$ & $2(2)$ & $5(2)$ & \\
\hline $18.6-25$ & $45(53)$ & $106(46)$ & \\
\hline $25.1-30$ & $29(34)$ & $75(33)$ & \\
\hline$>30$ & $9(11)$ & $43(19)$ & \\
\hline AFB & & & 0.148 \\
\hline 13-19 years & $45(51)$ & $141(61)$ & \\
\hline $20-24$ years & $27(30)$ & $57(25)$ & \\
\hline$\geq 25$ years & 17 (19) & $26(11)$ & \\
\hline Ever used contraceptives & & & $<0.001$ \\
\hline Yes & $10(9)$ & $103(46)$ & \\
\hline No & $100(91)$ & $119(54)$ & \\
\hline \multicolumn{4}{|l|}{ Alcohol use } \\
\hline Yes & $31(28)$ & $104(44)$ & \\
\hline No & $77(72)$ & $131(56)$ & \\
\hline Breastfeeding & & & $<0.001$ \\
\hline Yes & $85(77)$ & $228(96)$ & \\
\hline No & $26(23)$ & $9(4)$ & \\
\hline
\end{tabular}

Values are expressed as $\mathrm{n}(\%)$.

\section{Results}

Of the 350 women recruited in this study, 113 were cases and 237 controls (fig. 1). Table 1 shows the overall demographic characteristics as well as reproductive and nonreproductive factors. The mean age was 47.5 years (SD 14) for the cases and 45.5 years (SD 14.1) for the controls.

The distribution by regions of the country was not significantly different. There were more multiparous $(\geq 5)$ 
Table 2. Logistic regression analysis of the relationship between demographics, reproductive factors, and risk factors (Kampala 2012)

\begin{tabular}{|c|c|c|c|c|}
\hline & Crude OR (95\% CI) & $\mathrm{p}$ value & Adjusted OR (95\% CI) & $\mathrm{p}$ value \\
\hline \multicolumn{5}{|l|}{ CoC use } \\
\hline No & 1 & & 1 & \\
\hline Yes & $0.10(0.04,0.22)$ & $<0.001$ & $0.30(0.07,1.27)$ & 0.103 \\
\hline \multicolumn{5}{|c|}{$0.50(0.07,1.27)$} \\
\hline$<50$ years & 1 & & 1 & \\
\hline$\geq 50$ years & $1.14(0.68,1.92)$ & 0.013 & $1.91(0.98,3.74)$ & 0.058 \\
\hline \multicolumn{5}{|c|}{ Interaction CoC use $\times$ age } \\
\hline CoC use (yes & years) & & $0.13(0.02,0.83)$ & 0.031 \\
\hline \multicolumn{5}{|l|}{ Residence } \\
\hline Rural & 1 & & 1 & \\
\hline Urban & $1.42(0.43,1.16)$ & 0.171 & $1.50(0.81,2.80)$ & 0.201 \\
\hline \multicolumn{5}{|l|}{ Alcohol use } \\
\hline No & 1 & & 1 & \\
\hline Yes & $0.42(0.86,2.35)$ & 0.002 & $0.57(0.29,1.11)$ & 0.098 \\
\hline \multicolumn{5}{|l|}{ Parity } \\
\hline 1 & 1 & & & \\
\hline $2-4$ & $0.78(0.33,1.84)$ & 0.576 & & \\
\hline$\geq 5$ & $0.59(0.25,1.35)$ & 0.211 & & \\
\hline \multicolumn{5}{|l|}{ Breastfeeding } \\
\hline No & 1 & & 1 & \\
\hline Yes & $0.06(0.02,0.20)$ & $<0.001$ & $0.04(0.01,0.18)$ & $<0.001$ \\
\hline \multicolumn{5}{|l|}{$\mathrm{AFB}$} \\
\hline$<20$ & 1 & & 1 & \\
\hline $20-24$ & $1.48(0.84,2.63)$ & 0.178 & $1.96(0.97,3.96)$ & 0.061 \\
\hline$\geq 25$ & $1.83(0.91,3.67)$ & 0.087 & $1.27(0.58,2.81)$ & 0.550 \\
\hline \multicolumn{5}{|l|}{ Menarche } \\
\hline$\leq 14$ years & 1 & & & \\
\hline $15-16$ years & $1.57(0.91,2.70)$ & 0.105 & & \\
\hline$\geq 17$ years & $1.58(0.68,3.68)$ & 0.290 & & \\
\hline
\end{tabular}

women among the controls. There were no significant differences with regard to menarche and BMI between the groups. There were more women having their fullterm birth in the age brackets of 13-19 and 20-24 years among the controls. More women used CoCs among the controls, and more women breastfed among the controls. All significant differences were considered potential confounders and were adjusted for in the subsequent analyses.

A factor associated with increased odds of cancer, though not statistically significantly, was AFB $<20$ relative to $\geq 20$ years (adjusted OR $=1.96$; 95\% CI: 0.97, 3.96; $\mathrm{p}=0.061$ ), while ever having breastfed was associated with reduced odds of being a case (adjusted $\mathrm{OR}=0.04$; $95 \%$ CI: $0.01,0.18$ ). Use of alcohol (adjusted OR $=0.57$; $95 \%$ CI: $0.29,1.11$ ) had no significant association with being a cancer case (table 2).

Breast Cancer Risk Factors among Ugandan Women at a Tertiary Hospital
For women aged $\geq 50$ years, the odds of having cancer were lower (though not significantly so) among the ever $\mathrm{CoC}$ users compared to the never $\mathrm{CoC}$ users (adjusted $\mathrm{OR}=0.30$; 95\% CI: 0.07, 1.27). For the never CoC users, the odds of having cancer were higher among the $<50$-year-olds compared to the women aged $\geq 50$ years (adjusted OR $=1.91$; 95\% CI: 0.98, 3.74). However, these associations were not statistically significant.

There was an interaction between age and ever CoC use for the association between cancer and age. The OR of having cancer when younger women $(<50$ years) were compared to older ones ( $\geq 50$ years), and ever CoC use to never CoC use, was 0.13 (95\% CI: 0.02, 0.83). These data suggest that in women aged $\geq 50$ years, the risk for breast cancer in the group that had ever used $\mathrm{CoC}$ was significantly lower than in the group that had never used them (table 2). 


\section{Discussion}

While the risk factors investigated in this study are those that have been well established in many diverse high-risk as well as low-risk populations, including some in Africa, very few studies have specifically targeted women in Uganda and East Africa [4]. There are indications that the consensus on associations of breast cancer with some risk factors is not consistent [12]. With the additional knowledge that the incidence of breast cancer in Uganda is increasing at an unprecedented rate of $4 \%$ per annum [2] and the emerging picture of biological and epidemiological disparities in breast cancer between highand low-income countries [13-15], there will often be a need to re-explore these associations between breast cancer and previously known and/or newly suspected risk factors.

We therefore set out to explore commonly known risk factors associated with breast cancer among Ugandan women presenting at the two largest cancer referral institutions. We found that $\mathrm{CoC}$ use had a paradoxical, inverse relationship to breast cancer in women $<50$ years of age (premenopausal) who had ever used CoCs. They had lower odds of being a case than older women (postmenopausal) who had never used CoC. The role of CoC in oncogenesis is controversial or not wholly conclusive. One of the reasons is that the etiology of breast cancer is multifactorial and cannot be directly linked to any single factor, including estrogen. The epidemiological literature supports a highly complex interplay between different exposures and host characteristics as well as between exogenous and endogenous hormones and the individual's makeup [16].

There are two major potential mechanisms that have been postulated by which estrogen increases the risk of breast cancer: the first mechanism is stimulation of estrogen receptor-mediated transcription that results in cell proliferation, and the second mechanism is direct carcinogenesis through metabolic activation and direct binding of DNA. There is also a view that these two mechanisms act in an additive or even synergistic manner [17, 18]. A large study published in the Lancet [19] involving over 150,000 women suggested that CoC use increased the risk of breast cancer. In several other studies that followed, no significant risk was found, especially with the use of newer CoCs, and there was a minimal risk with older CoCs [16]. In a report on a UK cohort of 46,000 women published in 2007 spanning a 36-year period, there was no evidence of a substantially increased risk of any cancer, including breast cancer [20]. Noteworthy, there is no literature pertaining to women in sub-Saharan Africa. In the studies cited here, the number of black women included was very small. The IARC statement from 2005 that CoCs are classified as a group 1 carcinogen (the highest ranking) for breast and cervical cancers [21] only added to the inconsistencies in proof.

The explanation given for the level of cancer reduction seen in different parts of the world depends on factors such as the level of CoC usage, duration of use, age at stopping, and incidence of different cancers. More work is needed to quantify the likely balance between cancer risks and benefits in different parts of the world, including effects on mortality [20]. Treatment by the practicing physician is to be selective and specific to the patient's risk; women with a family history of breast cancer among 1st-degree relatives and with premalignant lesions should not take CoCs.

We found that coming from an urban setting did not lead to a higher risk for breast cancer than residing in a rural setting. We had anticipated that there would be differences between rural and urban settings due to perceived differences in lifestyle in terms of diet and other environmental factors. Increasing urbanization is suggested to be associated with an increased risk for breast cancer [22].

High parity was not protective against breast cancer. This is contrary to what we had anticipated $[12,23,24]$. In this study, the parous women had no lower odds of being a case (having breast cancer) than the nulliparous ones. The relationship between parity and breast cancer is known to be complex [15]. However, it is intricately related to estrogen exposure and interruption $[3,25]$. The interruption of estrogen synthesis during pregnancy is known to be protective against breast cancer, since estrogen is a driver of cellular proliferation $[12,24,25]$.

AFB was marginally related to increased odds of breast cancer $(p=0.061)$. The older the women were before having their first full-term birth, the higher the odds were of having breast cancer. This trend fits with the known physiological evidence of estrogen interruption, even though it was only inconclusively demonstrated here. Late pregnancy means a prolonged period of uninterrupted estrogen exposure. We also found that $70 \%$ of the Ugandan women had their menarche before the age of 17 years; the majority were multiparous (64\%) and had had $\geq 4$ live births, and most (90\%) had breastfed their babies.

Overall, these factors could contribute to the relatively low breast cancer incidence seen in Uganda as compared to richer nations [2], even if they do not seem to explain the fact that the incidence of breast cancer has nearly tri- 
pled over the last four decades in Uganda. It may therefore be worthwhile exploring the trends for these factors (menarche, parity, and breastfeeding) extensively over the past decades in Uganda.

BMI showed an inverse relationship to the odds of having breast cancer, though it was not statistically significant. This seemingly paradoxical relationship could be explained by the possibility that the cases had lost some of their body mass during the period preceding the diagnosis.

Breastfeeding has been inversely related to breast cancer risk in the general population [19] and it seemed protective against breast cancer in this study. The effect appeared to be greater than previously documented [26]; perhaps this was due to the fact that only a small number of women did not breastfeed. In Uganda, most women who bear children breastfeed them, thus making the task of getting sufficient numbers to robustly estimate the protective effect of breastfeeding a challenge. In the literature, only a slight reduction in the risk of breast cancer was reported among premenopausal women with increasing cumulative duration of lactation. There seems to be no evidence to support a reduction in the risk of breast cancer among postmenopausal women in many of the studies [27-34]; in other studies, no benefit was found $[12,23,34]$. It is also likely that the significant protective effect seen in this study is due to the fact that a significant number of participants were premenopausal. Lactation as a method for prevention of breast cancer has a strong appeal, since it is a potentially modifiable factor [26]. It is possible to strongly encourage women to breastfeed early and for a long period of time.

In order to promote public health in diverse populations and to provide further insight into breast cancer etiology, research needs to focus on multicultural differences and similarities in relation to the risk of cancer [35]. Therefore, a larger multi-country study to elucidate the protective effect of breastfeeding on breast cancer occurrence among pre- and postmenopausal African women is warranted. Breastfeeding is hypothesized to reduce the risk of breast cancer primarily through two mechanisms: differentiation of breast tissue and reduction of the lifetime number of ovulatory cycles (exposure to ovarian hormones) [24].

\section{Limitations of This Study}

Selection errors could have arisen from the possibility of leaving out an undiagnosed breast cancer early. However, the effect of this is likely to have been small given that the general population risk for breast cancer in Ugan- da is 1 in 3,000. The disease history was self-reported and therefore subject to recall bias; however, women mostly report their parity, breastfeeding, and alcohol use histories reliably [4]. Although reporting of the age at menarche may be less accurate, it should not have been reported any differently by cases and controls. The fact that there were only a small number of women who did not breastfeed or who consumed alcohol may have introduced a bias, though this was controlled for in the analysis. The lack of data on the duration (and amount where applicable) of exposure to risks such as tobacco smoking, alcohol use, CoC use, and breastfeeding is a weakness; this, however, might be dealt with in follow-up studies in this environment.

\section{Conclusion}

Breastfeeding seems to be associated with lower odds of breast cancer in this cohort of Ugandan women, and $\mathrm{CoC}$ use led to reduced odds of cancer in women $<50$ years of age.

\section{Acknowledgements}

The authors acknowledge support from the staff of the Breast Unit at Mulago, College of Health Sciences Teaching Hospital, Training Health Researchers into Vocational Excellence in East Africa (THRiVE; grant No. 087540), a Wellcome Trust-supported project, and an African Doctoral Dissertation Research Fellowship (ADDRF), as well as Ken Miller, MD, George Mutema, MD, $\mathrm{PhD}$, and the staff at the UCI.

\section{Disclosure Statement}

The authors declare no competing interest.

References

1 Gondos A, Brenner H, Wabinga H, Parkin DM: Cancer survival in Kampala, Uganda. $\mathrm{Br}$ J Cancer 2005;92:1808-1812.

2 Parkin DM, Nambooze S, Wabwire-Mangen F, Wabinga HR: Changing cancer incidence in Kampala, Uganda 1991-2006. Int J Cancer 2010;126:1187-1195.

3 Brinton LA, Figueroa JD, Awuah B, Yarney J, Wiafe S, Wood SN, Ansong D, et al: Breast cancer in sub-Saharan Africa: opportunities for prevention. Breast Cancer Res Treat 2014; 144:467-478.
Breast Cancer Risk Factors among

Ugandan Women at a Tertiary Hospital 
4 Huo D, Adebamowo CA, Ogundiran TO, Akang EE, Campbell O, Adenipekun A, Cummings S, Fackenthal J, Ademuyiwa F, Ahsan $\mathrm{H}$, Olopade OI: Parity and breast feeding are protective against breast cancer in Nigerian women. Br J Cancer 2008;98:992-996.

5 Ssali JC, Katongole-Mbidde E, Gakwaya A: Risk factors for breast cancer in Ugandan women: a case-control study. East Cent Afr J Surg 1992;1:9-13.

6 The World Bank: Data: Uganda (updated December 2010). http://data.worldbank.org/ country/uganda/ (accessed February 13, 2011).

7 Central Intelligence Agency: The World Fact Book (updated July 12, 2011). https://www. cia.gov/library/publications/the-world-factbook/geos/xx.html/ (accessed February 17, 2011).

8 Ministry of Finance, Planning, and Economic Development: Millennium Development Goals Report for Uganda 2010. Kampala, Ministry of Finance, Planning, and Economic Development, 2010.

9 Klugman J: Human Development Report 2010. The Real Wealth of Nations: Pathways to Human Development. New York, Palgrave Macmillan, 2010.

10 World Health Organization: Global Health Observatory Data Repository. Geneva, World Health Organization, 2006. http://apps.who. int/ghodata/?vid=20300/ (accessed February 15, 2011).

11 Elston CW, Ellis IO: Pathological prognostic factors in breast cancer. I. The value of histological grade in breast cancer: experience from a large study with long-term follow-up. Histopathology 1991;19:403-410.

12 Yang L, Jacobsen KH: A systematic review of the association between breastfeeding and breast cancer. J Womens Health (Larchmt) 2008;17:1635-1645.

13 Danforth DN Jr: Disparities in breast cancer outcomes between Caucasian and African American women: a model for describing the relationship of biological and nonbiological factors. Breast Cancer Res 2013;15:208.
14 Wheeler SB, Reeder-Hayes KE, Carey LA: Disparities in breast cancer treatment and outcomes: biological, social, and health system determinants and opportunities for research. Oncologist 2013;18:986-993.

15 Ademuyiwa FO, Edge SB, Erwin DO, Orom $\mathrm{H}$, Ambrosone CB, Underwood W 3rd: Breast cancer racial disparities: unanswered questions. Cancer Res 2011;71:640-644.

16 Casey PM, Cerhan JR, Pruthi S: Oral contraceptive use and risk of breast cancer. Mayo Clin Proc 2008;83:86-90; quiz 90-91.

17 Yager JD: Endogenous estrogens as carcinogens through metabolic activation. J Natl Cancer Inst Monogr 2000;27:67-73.

18 Yue W, Wang JP, Li Y, Fan P, Liu G, Zhang $\mathrm{N}$, Conaway $\mathrm{M}$, et al: Effects of estrogen on breast cancer development: role of estrogen receptor independent mechanisms. Int J Cancer 2010;127:1748-1757.

19 Collaborative Group on Hormonal Factors in Breast Cancer: Breast cancer and hormonal contraceptives: collaborative reanalysis of individual data on 53,297 women with breast cancer and 100,239 women without breast cancer from 54 epidemiological studies. Lancet 1996;347:1713-1727.

20 Hannaford PC, Selvaraj S, Elliott AM, Angus V, Iversen L, Lee AJ: Cancer risk among users of oral contraceptives: cohort data from the Royal College of General Practitioners' oral contraception study. BMJ 2007;335:651.

21 Cogliano V, Grosse Y, Baan R, Straif K, Secre$\tan$ B, El Ghissassi F: Carcinogenicity of combined oestrogen-progestagen contraceptives and menopausal treatment. Lancet Oncol 2005;6:552-553.

22 Colditz GA, Baer HJ, Tamimi RM: Breast cancer; in Schottenfeld D, Fraumeni JF (eds): Cancer Epidemiology and Prevention. New York, Oxford University Press, 2006, pp 9951012.

23 London SJ, Colditz GA, Stampfer MJ, et al: Lactation and risk of breast cancer in a cohort of US women. Am J Epidemiol 1990;132:1726.

24 Russo J, Rivera R, Russo IH: Influence of age and parity on the development of the human breast. Breast Cancer Res Treat 1992;23:211218.
25 Lambe M, Hsieh C, Trichopoulos D, Ekbom A, Pavia M, Adami HO: Transient increase in the risk of breast cancer after giving birth. $\mathrm{N}$ Engl J Med 1994;331:5-9.

26 Collaborative Group on Hormonal Factors in Breast Cancer: Breast cancer and breastfeeding: collaborative reanalysis of individual data from 47 epidemiological studies in 30 countries, including 50,302 women with breast cancer and 96,973 women without the disease. Lancet 2002;360:187-195.

27 Breast feeding and risk of breast cancer in young women. United Kingdom National Case-Control Study Group. BMJ 1993;307: $17-20$.

28 Yoo KY, Tajima K, Kuroishi T, et al: Independent protective effect of lactation against breast cancer: a case-control study in Japan. Am J Epidemiol 1992;135:726-733.

29 Katsouyanni K, Trichopoulos D, Boyle P, et al: Diet and breast cancer: a case-control study in Greece. Int J Cancer 1986;38:815-820.

30 Stuebe AM, Willett WC, Xue F, Michels KB: Lactation and incidence of premenopausal breast cancer: a longitudinal study. Arch Intern Med 2009;169:1364-1371.

31 Newcomb PA, Storer BE, Longnecker MP, Mittendorf R, Greenberg ER, Clapp RW, et al: Lactation and a reduced risk of premenopausal breast cancer. N Engl J Med 1994;330:81-87.

32 Palmer JR, Boggs DA, Wise LA, Ambrosone CB, Adams-Campbell LL, Rosenberg L: Parity and lactation in relation to estrogen receptor negative breast cancer in African American women. Cancer Epidemiol Biomarkers Prev 2011;20:1883-1891.

33 Kotsopoulos J, et al: Breastfeeding and the risk of breast cancer in BRCA1 and BRCA2 mutation carriers. Breast Cancer Res 2012;14:R42.

34 Duffy SW, Roberts MM, Elton RA: Risk factors for breast cancer: relevance to screening. J Epidemiol Community Health 1983;37: 127-131.

35 Pathak DR, Osuch JR, He J: Breast carcinoma etiology: current knowledge and new insights into the effects of reproductive and hormonal risk factors in black and white populations. Cancer 2000;88:1230-1238. 